\title{
Cultivo consorciado de Carthamus tinctorius L. (asteraceae) e Vigna unguiculata (L.) Walp. (leguminosae): efeitos na germinação, crescimento e anatomia
}

O cultivo consorciado de plantas oferece benefícios ambientais e sociais, porém os mecanismos morfoanatômicos e fisiológicos das plantas em consórcio têm sido pouco investigados e podem sofrer alteração por efeitos alelopáticos. O trabalho teve por objetivo analisar a germinação e crescimento de Carthamus tinctorius (cártamo) consorciado com Vigna unguiculata (feijão caupi) e caracterizar anatômica e histoquimicamente caules e folhas de $\mathrm{C}$. tinctorius. $\mathrm{O}$ experimento foi conduzido em campo, com uso de três tratamentos e três repetições. Os tratamentos consistiram em sistema de cultivo consorciado de cártamo e feijão caupi, e cultivos isolados de ambas as espécies. Foram analisadas a taxa de emergência e medições do corpo das plantas. As amostras vegetais foram coletadas aos 30,45 , 60 e 75 dias após a emergência para realização das análises de anatomia e histoquímica. O sistema de cultivo não teve influência sobre a emergência e o crescimento das plantas, nem modificações anatômicas e histoquímicas nos espécimes de cártamo. Isto indica que a interação entre as espécies é neutra, possibilitando o cultivo do Cártamo, cultura oleaginosa, em sistema de consórcio com uma cultura de subsistência como o feijão (leguminosa). Culturas com importante valor agregado tanto para a indústria, quanto para as atividades de subsistência.

\section{Intercropping cultivation of Carthamus tinctorius L. (asteraceae) and Vigna unguiculata (L.) Walp. (leguminosae): effects on germination, growth and anatomy}

Intercropping plants offer environmental and social benefits, but the morphophysiological and physiological mechanisms of intercropping plants have been little investigated and may change due to allelopathic effects. The objective of this work was to analyze the germination and growth of plants of Carthamus tinctorius (safflower) intercropped with Vigna unguiculata (cowpea), and to characterize anatomically and histochemically C. tinctorius stems and leaves. The experiment was conducted in the field, using three treatments and three repetitions. The treatments consisted of intercropping system of safflower and cowpea, and isolated crops of both species. The emergence rate and plant body measurements were analyzed. Plant samples were collected at $30,45,60$ and 75 days after emergence for anatomy and histochemical analysis. The cultivation system had no influence on plant emergence and growth, nor anatomical and histochemical changes in safflower specimens. This indicates that the interaction between species is neutral, allowing the cultivation of safflower, oilseed, in a intercropping system with a subsistence crop such as beans (legume). Crops with significant benefit for both industry and subsistence activities.

Keywords: Safflower; Consortium; Vegetative growth; Cowpea.

Topic: Desenvolvimento, Sustentabilidade e Meio Ambiente

Reviewed anonymously in the process of blind peer.
Received: 02/07/2021 Approved: 28/07/2021
Émile Rocha de Lima (iD)

Universidade Federal do Rio Grande do Norte, Brasil http://lattes.cnpq.br/9658828504533374 http://orcid.org/0000-0002-8596-1403 mli.18@hotmail.com

Raimunda Adlany Dias da Silva

Universidade Federal do Rio Grande do Norte, Brasil http://lattes.cnpq.br/1816809780487274

http://orcid.org/0000-0002-3600-6186 adlanydias@gmail.com

Gabrielle Macedo Pereira (ic

Universidade Federal do Rio Grande do Norte, Brasil

http://lattes.cnpq.br/7975202296724439

http://orcid.org/0000-0002-6638-2035

gabrielle.macp@gmail.com
Juliana Espada Lichston (iD

Universidade Federal do Rio Grande do Norte, Brasil

http://lattes.cnpq.br/0727435909982933

http://orcid.org/0000-0002-4042-4524

j.lichston@gmail.com
Referencing this:

LIMA, É. R.; SILVA, R. A. D. S.; PEREIRA G. M.; LICHSTON J. E.. Cultivo consorciado de Carthamus tinctorius L. (asteraceae) e Vigna unguiculata (L.) Walp. (leguminosae): efeitos na germinação, crescimento e anatomia. Revista Ibero Americana de Ciências Ambientais, v.12, n.7, p.352-361, 2021. DOI:

http://doi.org/10.6008/CBPC2179-6858.2021.007.0032 


\section{INTRODUÇÃO}

O consórcio se destaca em ao monocultivo, propiciando maior vantagem para o produtor, pois, é possível o melhor aproveitamento dos recursos naturais como nutrientes, previne as doenças, pragas e a predação por insetos. O cultivo consorciado diminui ainda a necessidade de fertilizantes químicos e pesticidas, reduz a poluição ambiental, diminui os custos de produção e melhora o rendimento do produtor em agrossistemas, bem como aumentando seus lucros (ZHANG et al., 2013).

Porém, o consórcio pode resultar em variações significativas na morfologia, tais como altura de plantas, arranjo de folhas, número de ramos laterais ou variações fisiológicas, tais como modo de crescimento, comprimento da fase de crescimento, dentre outras (DARABAD et al., 2011). É necessária a verificação de alguns parâmetros, dentre eles a análise de crescimento, ferramenta a qual permite conhecer a eficiência e habilidade de adaptação das plantas às condições ambientais que estão inseridas (CARVALHO et al., 2009).

Nesse contexto, esse estudo avaliou o desenvolvimento do Carthamus tinctorius L. (cártamo) uma herbácea, oleaginosa pertencente à família Asteraceae originária da Ásia e África (DAJUE et al., 1999), que vem sendo estudada em sistemas de cultivos consorciados devido a sua crescente importância econômica (SCHRÖDER et al., 2012).

O cártamo possui considerável valor econômico, pois apresenta versatilidade de usos como o medicinal, farmacêutico, indústria de cosméticos, especiarias, forragem e flor de corte (ABUD et al., 2010; FARRAN et al., 2009). O ciclo de cultivo da cultura é curto, aproximadamente 130 a 150 dias (GALANT et al., 2015; SANTOS et al., 2015), quando é cultivado no semiárido do Nordeste brasileiro reduz para 75 dias (SILVA et al., 2021) com teor de óleo nas sementes variando de $24,0 \%$ a $30 \%$ em diferentes condições de cultivo (ZANÃO JUNIOR et al., 2017) e entre as cultivares 30\% a $34 \%$ ( SILVA et al., 2021).

O óleo do cártamo é composto quimicamente por ésteres glicerídeos insaturados (90\%), do tipo 72 e 78\% de sua composição de ácido graxo linoleico, 16 a 20\% de ácido oleico, (HALL III, 2016) e apresentam propriedades antioxidantes (ZHOU et al., 2014). Este é proposto como matriz para produção de biocombustíveis, uma alternativa ao combustível diesel e combustíveis aditivos (YAU et al., 2010; FLEMMER et al., 2015; SILVA et al., 2021) é uma cultura potencial para produção e biocombustíveis em regiões semiáridas (SILVA et al., 2019).

Atualmente o cártamo é cultivado em 21 países, com destaque para o Cazaquistão, o qual produziu 224.809 toneladas no ano de 2017. Porém, ainda são escassos trabalhos que contemplem as variações morfológicas e anatômicas do cártamo em condições de campo, principalmente quando cultivado em consórcio.

Dentre as várias culturas utilizadas em sistemas de consórcio no Brasil, o feijão caupi, Vigna unguiculata (L.) Walp., tem sido amplamente utilizado pois, além de incrementar a produtividade de alimentos, é uma cultura de ciclo curto e apresenta baixa habilidade competitiva, oferecendo vantagens às outras espécies associadas (FREIRE FILHO, 2011). 
Diante do exposto, essa pesquisa objetivou investigar o desenvolvimento do Carthamus tinctorius L. e Vigna unguiculata (L.) Walp. cultivadas isoladamente e em sistema de consórcio, por meio da análise de germinação e crescimento das plantas, além da caracterização anatômica e histoquímica do caule e folha das espécies avaliadas.

\section{MATERIAIS E MÉTODOS}

\section{Área de estudo}

O cultivo das espécies em sistemas isolado e consorciado foi realizado nas dependências da Escola Agrícola de Jundiaí - Macaíba/RN (50 51' 30" S e 35o 21' 14" W), a 11 m de altitude, e temperatura média de 27,1 으 em delineamento de blocos casualizados $1 \times 2 \times 1$, sendo 1 sistema de cultivo isolado (monocultivo) do feijão caupi, 2 sistemas de consorciado (feijão caupi e cártamo) e 1sistema de cultivo isolado (monocultivo) de cártamo.

A área experimental foi de $22,5 \mathrm{~m}^{2}$, dividida em nove lotes de $2,5 \mathrm{~m}^{2}$ cada um com distância de $1,5 \mathrm{~m}$ entre eles, sendo três lotes por tratamento: T1 - monocultivo de cártamo; T2 - consórcio de cártamo e feijão; e T3 - monocultivo de feijão, cada um com três repetições. $O$ arranjo se deu de forma alternada de modo que as parcelas de um mesmo tratamento não se repetissem na mesma linha ou coluna (Figura 1).

Para o cultivo isolado do cártamo, a distância entre linhas foi de $0,5 \mathrm{~m}$ e entre covas $0,2 \mathrm{~m}$; já para o feijão caupi adotou-se 0,5 entre linhas e 0,4 entre covas. No cultivo consorciado adotou-se o mesmo delineamento, alternando apenas fileiras de cártamo com fileiras de feijão caupi como representado na (Figura 1).

(A)

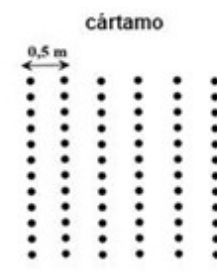

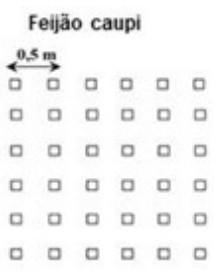
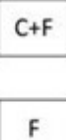

Figura 1: Disposição dos cultivos em campo. A - Arranjo das plantas dentro das parcelas. Cártamo (círculos), feijão caupi (quadrados). B - Arranjo espacial das parcelas dos tratamentos de monocultivo de cártamo (C), monocultivo de feijão caupi (F) e do consórcio de cártamo com feijão caupi (C+F).

O solo apresentou como características: cálcio $=1,32 \mathrm{cmol}_{c} \mathrm{dm}^{3}$, magnésio $=0,59 \mathrm{cmol}_{c} \mathrm{dm}^{3}$, alumínio $=$ $0,0 \mathrm{cmol}_{c} \mathrm{dm}^{3}$, hidrogênio + alumínio $=1,26 \mathrm{cmol}_{c} \mathrm{dm}^{3}$, fósforo $=7 \mathrm{cmol}_{c} \mathrm{dm}^{3}$, potássio $=56 \mathrm{cmol}_{c} \mathrm{dm}^{3}$, sódio $=$ $11 \mathrm{cmol}_{\mathrm{c}} \mathrm{dm}^{3}$, e pH=6,18. Foi realizada, antes do plantio, a correção do solo seguindo recomendações da EMPARN com base no utilizado para cultura do girassol, mesma família botânica do cártamo, que são $50 \mathrm{~kg} /$ ha de superfosfato simples $\left(20 \% \mathrm{P}_{2} \mathrm{O}_{5}\right), 20 \mathrm{~kg} / \mathrm{ha}$ de ureia $(45 \% \mathrm{~N})$ e $20 \mathrm{~kg} / \mathrm{ha}$ de cloreto de potássio $(58 \%$ 
K ${ }_{2} \mathrm{O}$ ) (CASTRO et al., 1996), padrão para as espécies.

Para as coletas de dados considerou-se como borda as duas linhas laterais dentro de cada parcela, sendo estas desconsideradas. A irrigações se ocorreu durante todo o estudo, as quais eram realizadas a cada três dias por meio do sistema de mini aspersão. A retirada de plantas daninhas foi realizada de forma manual sempre que necessário.

\section{Taxa de emergência}

Foi mensurado o número de plântulas emergidas de cártamo e feijão caupi por meio de contagem, segundo orientação de Nascimento et al. (2014) que consideram emergidas as plântulas que apresentam os dois primeiros folíolos acima da superfície do solo totalmente livres do substrato. Os dados obtidos foram submetidos ao teste $\mathrm{T}$ não pareado a $5 \%$ de probabilidade de erro.

\section{Análise de crescimento}

As avaliações das características de crescimento para o cártamo e feijão caupi tiveram a duração de 75 dias, onde a primeira medição se deu trinta dias após a emergência das plântulas, e as demais em um intervalo de 15 dias. Na última coleta dos dados de crescimento (altura e espessura do caule) aos 75 dias após a emergência, as plantas estavam no início do período de prefloração. Para a coleta e compilação dos dados do presente estudo foram desconsideradas as duas linhas correspondentes à borda.

Duas plantas de cada um dos 9 lotes avaliados foram selecionadas aleatoriamente, sendo etiquetadas para realização das medições de altura das plantas $(\mathrm{cm})$ e diâmetro dos caules $(\mathrm{mm})$. Os dados obtidos foram submetidos ao teste $\mathrm{T}$ não pareado, a $5 \%$ de probabilidade de erro, com a utilização do software GraphPadPrism V5.

\section{Anatomia e histoquímica}

Para análise morfoanatômica do cártamo, foram selecionadas duas plantas de cada lote e coletadas amostras de caule (do primeiro ao quinto nó) partindo do ápice para a base, e folhas totalmente expandidas situadas no sexto nó, partindo do ápice para a base. As amostras foram coletadas nas mesmas datas das aferições de crescimento vegetativo das plantas, aos 30 dias, 45, 60 e 75 dias após a emergência das plântulas. Todas as amostras foram conservadas em etanol 70\% Para posteriormente serem feitas secções transversais do caule e da região medial do limbo foliar, seguindo técnicas convencionais de corte à mão livre.

Os cortes foram clarificados com o auxílio de hipoclorito de sódio $1 \%$, e para a coloração foi o utilizado os reagentes: Azul de Alcian 1\% e Safranina 1\% para posteriormente serem confeccionadas lâminas semipermanentes. Foram realizados ainda, testes histoquímicos para detecção de lipídios utilizando-se Sudan Black 0,07\%; para amido com Lugol 5\% e para substâncias fenólicas com o uso de Cloreto férrico (KRAUS et al., 1997). 
Observações e captura de imagens foram realizadas com utilização do microscópio de luz modelo Nikon Eclipse Ni com porta Speed modelo DS-Ri1 da Nikon.

\section{RESULTADOS}

\section{Taxa de germinação}

A comparação entre taxa de emergência dos espécimes de cártamo cultivado em monocultivo (93\%) e do cártamo consorciado com feijão $(70,4 \%)$, bem como para o feijão cultivado em monocultivo $(71,3 \%)$ e do feijão consorciado com o cártamo (50\%), apesar da tendência numérica, não diferiram significativamente entre os tratamentos (Figura 2), evidenciando que o cultivo consorciado não interferiu na variável analisada.

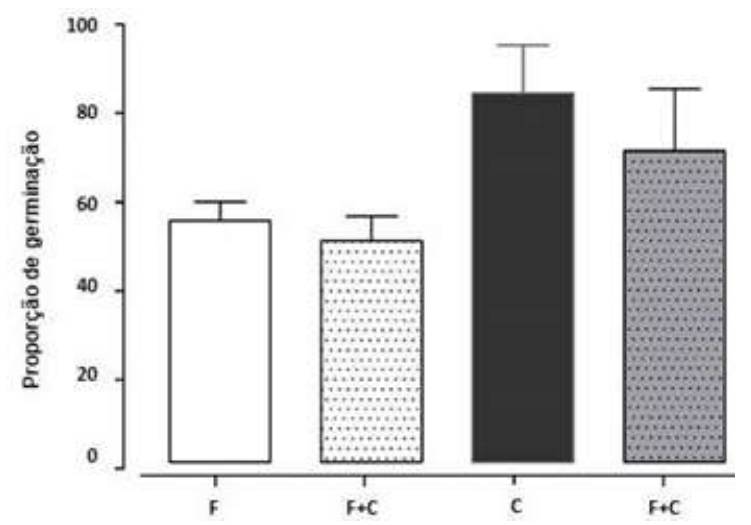

Figura 2: Taxa de emergência das plântulas em campo: $\mathrm{C}$ - monocultivo de cártamo; $\mathrm{C}+\mathrm{F}$ - emergência do cártamo consorciado com feijão; $\mathrm{F}$ - monocultivo de feijão; $\mathrm{F}+\mathrm{C}$ - emergência do feijão consorciado com cártamo. Teste $\mathrm{t}$ $(P<0,05)$.

\section{Análise de Crescimento}

Avaliando-se a altura e diâmetro dos caules das plantas de cártamo verificou-se que os espécimes cultivados em consórcio com o feijão não apresentaram diferenças estaticamente significativas $(P<0,05)$ quando comparados com o monocultivo. Porém observa-se apenas uma tendência de aumento da altura do feijão caupi quando consorciado com o cártamo (Figura 3).
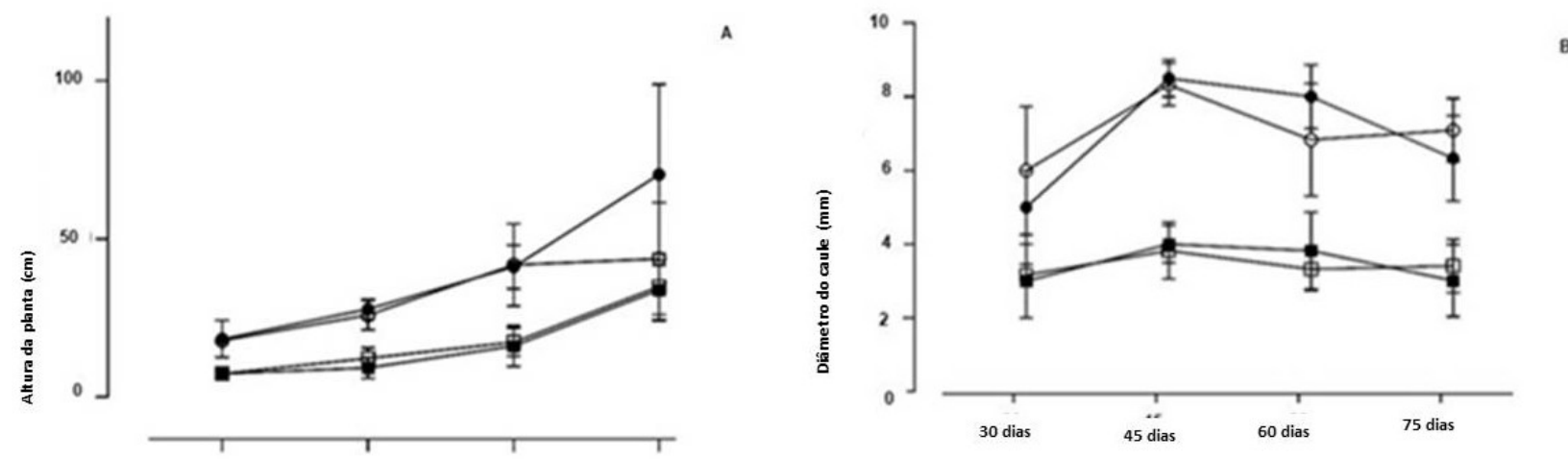

Figura 3: Altura das plantas (A); Diâmetro caulinar (B) para teste $t(P<0,05)$ no eixo $Y$ e dias pós a germinação no eixo X. - Medidas do cártamo consorciado com feijão; $\square$ - Monocultivo de cártamo; • - Medidas do feijão consorciado com cártamo; O - Monocultivo de feijão.

Para o diâmetro do caule, observou-se que tanto o cártamo quanto o feijão em consórcio apresentaram comportamento similares, demonstrando uma sutil tendência à redução da espessura do 
caule no estágio de prefloração (75 dias de germinadas). Os maiores valores de diâmetro do caule encontrados foram aos 45 dias após a emergência, observando-se um leve decréscimo após esse tempo, tanto para o feijão caupi quanto para o cártamo (Figura 3).

\section{Morfoanatomia e histoquímica de Cartamus tinctorius}

Não foram observadas alterações morfoanatômicas nas folhas e caules de cártamo submetidos aos dois tipos de tratamento (monocultivo e consórcio), em nenhum dos tempos de crescimento.

Na análise anatômica de cártamo, constatou-se no caule, uma epiderme unisseriada recoberta por espessa camada de cutícula com estriações e cera epicuticular (Figura 4A). Próximo à epiderme foram observadas três a quatro camadas de células de colênquima, que se intercalavam com o parênquima, formando o córtex. Notou-se a presença de esclerênquima associado aos feixes vasculares. Cada feixe vascular possuía um ducto próximo, com lúmen isodiamétrico, delimitado por uma camada de células epiteliais com paredes delgadas (Figura 4 A, B).

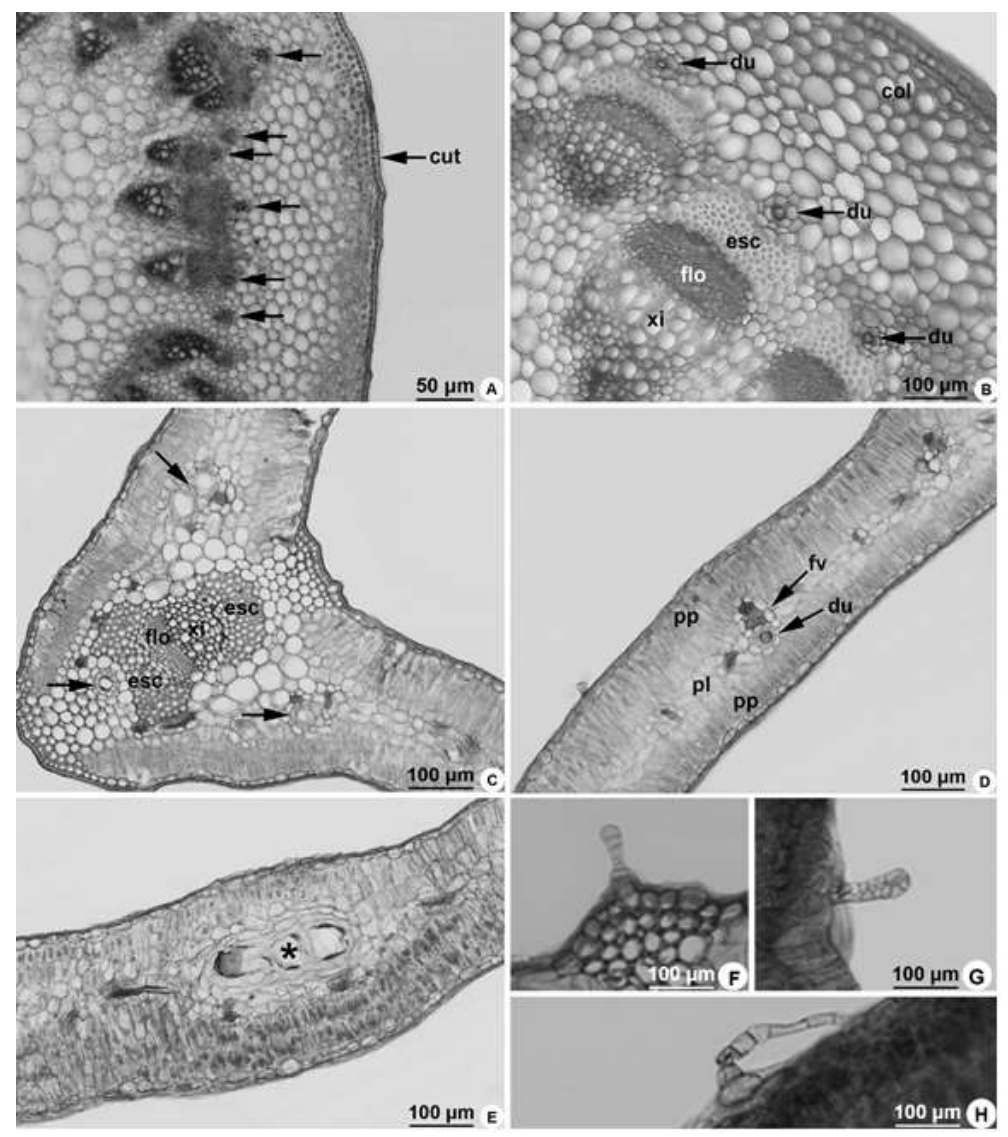

Figura 4: Secções transversais do caule (A-B) e folha (C-H) de C. tinctorius L.: A-B - Detalhe dos feixes vasculares, evidenciando os ductos (setas) e as células epidérmicas realçando a cutícula (cut); B - Detalhe da organização dos feixes vasculares e ductos (du); C - Disposição das células na nervura mediana da folha, evidenciando ductos (setas); D

- Lâmina foliar com presença de ducto próximo ao feixe vascular; $\mathrm{E}$ - Detalhe de ductos associados no mesofilo (asterisco); F e G - Tricomas glandulares; $\mathrm{H}-$ Tricoma tector. (cut = cutícula; du = ducto; col = colênquima; $\mathrm{xi}$ = xilema; $\mathrm{flo}=$ floema; esc = esclerênquima; $\mathrm{pp}$ = parênquima paliçádico; $\mathrm{pl}=$ parênquima lacunoso; $\mathrm{fv}$ = feixe vascular).

As folhas do cártamo mostraram-se pequenas e compactas, e a epiderme unisseriada, formada por células que variaram de tabulares a irregulares, e com uma espessa camada cuticular cobrindo toda a superfície foliar. Verificou-se a presença de tricomas multicelulares, glandulares e tectores (Figura 4F, G, H), 
nas superfícies abaxial e adaxial. Abaixo da epiderme na nervura central, encontraram-se algumas camadas de colênquima, seguidas pelas células do parênquima, onde estavam imersos ductos secretores próximos aos feixes vasculares (Figura 4C). O mesofilo apresentou-se isobilateral, com diversas camadas de parênquima paliçádico (Figura 4D).

Os ductos na folha eram delimitados por várias camadas de células e possuíam lúmen mais extenso do que o observado no caule (Figura 4E). Os ductos e os feixes vasculares encontravam-se separados apenas por uma camada de células da endoderme, dispersos por toda a lâmina foliar, apresentando-se em igual proporção e densidade em espécimes de cártamo dos dois sistemas de cultivo.

Na caracterização histoquímica dos órgãos (caule e folha) e ductos de cártamo, verificou-se que a substância presente nas estruturas secretoras (ductos) possuía natureza mista (lipídica e fenólica), com maior influência de compostos lipofílicos, reagindo positivamente para substâncias lipofílicas (teste com Sudan Black).

\section{DISCUSSÃO}

Dentre espécies da mesma família do feijão caupi (Leguminoseae) como a C. spectabilis, Pereira Nogueira et al. (2019) observaram que em sistema de cultivo consorciado com o milho a espécie obteve bons resultados de produtividade. Em sistema de consórcio com a mamoneira, espécie oleaginosa, o feijão foi indicado como a melhor cultura companheira em comparação com o gergelim (FURTADO et al., 2014). Corroborando com o observado no presente estudo, no qual se verificou que feijão caupi (cultura de subsistência) e cártamo (cultura oleaginosa) podem ser cultivados em sistema de consórcio sem que haja prejuízo para ambas, quanto aos parâmetros avaliados.

As taxas de germinação em campo para o feijão, próximas a 90\%, foram verificadas por Smiderle et al. (2008), pouco acima do que foi observado neste experimento. Para o cártamo, as taxas de emergência foram semelhantes às verificadas por Kaya et al. (2003) observaram taxas de germinação que variaram entre $82,2 \%$ a $91,1 \%$ em casa de vegetação e superiores as observadas por Menegaes et al. (2021) os quais verificaram valores entre $72 \%$ e $76 \%$. Neves et al. (2019) observaram taxas de emergência de plântulas de cártamo inferiores, cerca de $30 \%$ para o controle e $50 \%$ com extrato de soja, considerado pelos autores como estimulador da germinação e desenvolvimento do cártamo. A ausência de dados na literatura acerca de taxas de germinação em campo para cártamo tanto em monocultivo, quanto em sistema de consórcio, evidencia a importância da presente pesquisa e indica a necessidade de outros estudos com a planta nestas condições.

A ausência de diferenciação acentuada na altura das plantas cultivadas isoladamente e em consórcio, coincidiram com os relatos de Rodrigues et al. (2014), que também não obtiveram resposta significativa para a altura de plantas de girassol, espécie da mesma família do cártamo (Asteraceae), quando cultivadas em sistema de consorciação com o feijão caupi. Segundo esses autores, a competição de girassol com feijão, em todas as populações de plantas, não afetou de forma significativa as variáveis de crescimento corroborando com observado no presente estudo. Porém, foi visível uma pequena tendência de beneficiamento do feijão 
Cultivo consorciado de Carthamus tinctorius L. (asteraceae) e Vigna unguiculata (L.) Walp. (leguminosae): efeitos na germinação, crescimento e

quando consorciado, apenas no estágio de prefloração. Oliveira Filho et al. (2016) verificaram que a interação de uma oleaginosa da família Euphorbiaceae, a mamona, afetou de forma negativa a cultura do feijão. A redução na taxa de crescimento caulinar no intervalo final de crescimento das culturas (entre 60 - 90 dias) pode estar relacionada com a formação de frutos e, portanto, alta demanda de energia e aumento de fitomassa, que será carreada para as novas estruturas e para manutenção das já existentes (ARAÚJO et al., 2014).

A ausência de diferença entre os tratamentos indica possível efeito de equivalência entre a competição intra e interespecífica do cultivo isolado e consorciado. Essa ausência é resultado da interação interespecífica de espécies que possuem requisitos nutricionais diferentes, sistemas radiculares, de fotossíntese, comprimento e altura também diferentes, o que causa ausência de competição durante as fases de crescimento (DARABAD et al., 2011). O cártamo também é tolerante à alelopatia de culturas de outras famílias como capim napier (Pennisetum purpureum) e citronela (Cymbopogon) (SCHAFFNER et al., 2017; SILVEIRA et al., 2016). O que pode explicar a leve tendência do aumento no tamanho das plantas do feijão, e não prejuízo nas plantas de cártamo, quando consorciados, já que a estrutura radicular do feijão (mais rasa) difere da organização radicular do cártamo (mais profunda).

O aumento na disponibilidade de nitrogênio no solo, frente ao cultivo consorciado com o feijão, não interferiu no crescimento vegetativo de cártamo. Este fato foi também verificado por Yau et al. (2010) ao estudarem a resposta de cártamo à adubação nitrogenada. Os pesquisadores relataram que a explicação mais plausível para a ausência de resposta à aplicação de nitrogênio é que o cártamo tem raízes profundas, que podem até captar nutrientes que foram lixiviados e acumulados nas camadas mais profundas do solo, onde outras culturas de raízes rasas não têm acesso. Silva (2019) também verificou que a adição de adubo rico em nitrogênio não teve influência sobre os padrões fisiológicos, desenvolvimento e produtividade da cultura.

Com relação às características morfoanatômicas nos caules e folhas de cártamo, a ausência de modificações em consórcio difere de alguns autores, que afirmam que o consorciamento de cártamo pode resultar em variações fisiológicas e morfológicas na cultura (DARABAD et al., 2011). Pourghasemian et al. (2019) apontam que os diferentes genótipos do cártamo se comportam diferente quando submetido a diversos níveis cádmio e agentes estressores podendo demonstrar alterações na sua fisiologia.

Na família Asteraceae, ocorrem dois sistemas secretores, tricomas glandulares na superfície dos órgãos e ductos secretores internos (BARTOLI et al., 2011). A análise anatômica dos tricomas, relacionados com a análise morfológica externa dos órgãos vegetativos possibilita a diferenciação de espécies (BUDEL et al., 2009; EKEKE et al., 2020). Evidenciando assim a representatividade das análises anatômicas como valor taxonômico.

Plantas da família Asteraceae, em geral, são ricas em compostos fenólicos predominantemente lipofílicos (GLÓRIA et al., 2006). A secreção por meio de ductos e tricomas em asteráceas é composta por óleos essenciais, lipídios, resinas, lactonas sesquiterpênicas, alcaloides, substâncias pécticas, taninos e 
flavonoides (BARTOLI et al., 2011).

Mesmo que o cultivo consorciado não tenha causado modificações estruturais, deve-se atentar para o semeio de plantas em uma quantidade adequada, pois a alta densidade de plantas de outras culturas em consórcio com o cártamo causa competição intensa, o que diminui as características de crescimento e os componentes de produção (DARABAD et al., 2011).

\section{CONCLUSÕES}

A ausência de alterações significativas na germinação e crescimento das duas espécies consorciadas, e manutenção da integridade morfoanatômica e histoquímica do cártamo, indicam que a interação entre as duas espécies foi neutra. Sendo assim, torna-se viável o cultivo do cártamo, uma oleaginosa, como cultura extrativista, de valor comercial para vários ramos da indústria e o feijão caupi, uma leguminosa de importância alimentar, muito cultivada como cultura de subsistência. O cultivo consorciado das espécies estudadas pode gerar renda, desenvolvimento e abastecimento à agricultura familiar.

AGRADECIMENTOS: À CAPES, pela concessão de bolsa de mestrado para a primeira autora; à Escola Agrícola de Jundiaí - EAJ, pela viabilização do trabalho em campo; ao Prof. Dr. Ronaldo Angelini e em especial ao Danyhelton Dantas pelo auxílio com as análises dos dados e ao Ministério da Ciência, Tecnologia, Inovações e Comunicações - MCTIC pelo suporte financeiro.

\section{REFERÊNCIAS}

ABUD, H. F.; GONÇALVES, N. R.; REIS, R. D. G. E.; GALLÃO, M. I.; INNECCO, R.. Morfologia de sementes e plântulas de cártamo. Revista Ciência Agronômica, v.41, n.2, p.259-265, 2010.

ARAÚJO, A. C.; ALOUFA, M. A. I.; SILVA, A. J. N.; COSTA, A. A.; SANTOS, I. S.. Análise não destrutiva de crescimento do gergelim consorciado com feijão caupi em sistema orgânico de cultivo. Revista Brasileira de Agroecologia, v.9, n.1, p.259-268, 2014.

BARTOLI, A.; GALATI, G.; TORTOSA, R. D.. Anatomical studies of the secretory str uctures: glandular trichomes and ducts, in Grindelia pulchella Dunal (Astereae, Asteraceae). Flora, v.206, p.1063-1068, 2011. DOI: http://doi.org/10.1016/i.flora.2011.07.012

BUDEL, J. M.; DUARTE, M. D. R.. Análise morfoanatômica comparativa de duas espécies de carqueja: Baccharis microcephala DC. e B. trimera (Less.) DC., Asteraceae. Brazilian Journal of Pharmaceutical Sciences, v.45, n.1, p.75-85, 2009. DOI: http://doi.org/10.1590/S1984$\underline{82502009000100009}$

CARVALHO, C. A. L.; DANTAS, A. C. V. L.; PEREIRA, F. A. C.; SOARES, A. C. F.; MELO FILHO, J. F.; OLIVEIRA, G. J. C.. Tópicos em Ciências Agrárias. Cruz das Almas: Universidade Federal do Recôncavo da Bahia, Centro de Ciências Agrárias, Ambientais e Biológicas, 2009.
CASTRO, C.; CASTIGLIONI, V. B. R.; BALLA, A.; LEITE, R. M. V. B. C.; KARAM, D.; MELLO, C. H.; GUEDES, L. C. A.; FARIAS, J. R. B.. A cultura do girassol Circular Técnica n.913 da Empresa Brasileira de Pesquisa Agropecuária. Embrapa, 1996.

DAJUE, L.; MUNDEL, H. H.. Carthamus tinctorius L. Promoting the conservation and use of underutilized and neglected crops. Roma: Institute of Plant Genetics and Crop Plant Research, Gatersleben/International Plant Genetic, 1996.

DARABAD, G. R.; KANDI, M. A. S.; BARMAKI, M.; SHARIFI, R. S.; HOKMALIPOUR, S.; ASADI, S.. Evaluations of yield and yield components in potato-safflower intercropping. Australian Journal of Basic and Applied Sciences, v.5, n.11, p.1423-1428, 2011.

EKEKE, C.; AGOGBUA, J. U.. Comparative Taxonomic study on Crotalaria L. from some parts of South-Eastern Nigeria. Bulletin of Pure and Applied Sciences-Botany, v.39, n.2, p.94-105, 2020. DOI: http://doi.org/10.5958/2320$\underline{3196.2020 .00015 .4}$

FARRAN, M. T.; BARBOUR, G. W.; USAYRAN, N. N.; YAU, S. K.; SALEM, R.; JABBOUR, C.. Performance of male broiler chicks fed practical diets containing graded levels of de-hulled extruded safflower meal during the starter period. Antalya: Proceedings of the Second Mediterranean Summit of WPSA, v.2 p.507-509, 2009. 
FLEMMER, A. C.; FRANCHINI, M. C.; LINDSTRÖM, L. I. Description of safflower (Carthamus tinctorius) phenological growth stages according to the extended $\mathrm{BBCH}$ scale. Annals of Applied Biology, v.166, p.331-339, 2015. DOI: http://doi.org/10.1111/aab.12186

FURTADO, G. D. F.; SOUSA, A. D. S.; SOUSA JUNIOR, J. R.; SOUSA, F. R. M.; LACERDA, S. D. A.; SILVA, S. S. Rendimento e correlações da mamoneira consorciada com feijão-caupi e gergelim no semiárido paraibano. Revista Brasileira de Engenharia Agrícola e Ambiental, v.18, n.9, p.892-898, 2014. DOI: http://doi.org/10.1590/18071929/agriambi.v18n09p892-898

GALANT, N. B.; SANTOS, R. F.; SILVA, M. A.. Melhoramento de cártamo (Carthamus tinctorius L.). Acta Iguazu, v.4, n.1, p.14-25, 2015.

GLÓRIA, B. A.; CARMELLO-GUERREIRO, S. M.. Anatomia Vegetal. 6 ed. Viçosa: Universidade Federal de Viçosa, 2006.

HALL III, C.. Overview of the Oilseed Safflower (Carthamus tinctorius L.). Fargo: North Dakota State University, 2016. DOI: http://doi.org/10.1016/B978-0-08-100596-5.00030-5

KAYA, M. D.; OZTURK, A.. Effects of different soil salinity levels on germination and seedling growth of safflower (Carthamus tinctorius L.). Turk. J. Agric. For., v.27, p.221227, 2003.

KRAUS, J. E.; ARDUIM, M.. Manual básico de métodos em morfologia vegetal. Rio de Janeiro: EdUR, 1997.

MENEGAES, J. F.; BELLÉ, R. A.; NUNES, U. R.. Potencial fitossanitário de sementes de cártamo armazenadas em diferentes condições de conservação e períodos. Revista Acta Ambiental Catarinense, v.18, n.1, p.169-180, 2021.

NASCIMENTO, I. L.; MARACAJA, P. B.; SILVA, M. L. S.; SILVA, F. M.; COELHO, D. C.. Emergência e crescimento inicial de plântulas de Caesalpinia ferrea Mart. ex Tul. var leiostachya Benth. Em diferentes tipos de solos, ACSA - Agropecuária Científica do Semiárido, v.10, n.2, p.42-49, 2014. DOI: http://doi.org/10.30969/acsa.v10i2.258
NEVES, A. C.; JÚNIOR, E. S.; DAL POZZO, D. M.; SCHAFFNER, R. A.; CRIPA, F. B.; SANTOS, R. F.. Interferência alelopática de soja sobre a germinação de Carthamus tinctorius. Revista Brasileira de Energias Renováveis, v.8, n.4, 2019. DOI: http://doi.org/10.5380/rber.v8i4.65752

NOGUEIRA, C. H. P.; CORREIA, N.; GOMES, L. J. P.; FERREIRA, P. S. A. H.. Selectivity of bentazon and nicosulfuron in Crotalaria spectabilis intercropped with maize culture. Revista Caatinga, v.32, n.2, p.381-389, 2019. DOI: http://doi.org/10.1590/1983-21252019v32n211rc

OLIVEIRA FILHO, A. F.; BEZERRA, F. T. C.; PITOMBEIRA, J. B.; DUTRA, A. S.; BARROS, G. L.. Eficiência agronômica e biológica nos consórcios da amoneira com feijão-caupi ou milho. Revista Ciência Agrônomica, v.47, n.4, p.729-736, 2016.

POURGHASEMIAN, N.; LANDBERG, T.; EHSANZADEH, P.; GREGER, M.. Different response to Cd stress in domesticated and wild safflower (Carthamus spp.). Ecotoxicology and Environmental Safety, v.171, p.321-328, 2019. DOI: http://doi.org/10.1016/i.ecoenv.2018.12.052

RODRIGUES, C. F.; BEZERRA, A. R.; PITOMBEIRA, J. B.; CARVALHO, C. M.; SILVA, L. L.; FEITOSA, S. O.. Sistema de consórcio do girassol, feijão-de-corda e amendoim em series de substituição. Revista Brasileira de Agricultura Irrigada, v.8, n.3, p.256-269, 2014. DOI: http://doi.org/10.7127/rbai.v8n300207

SANTOS, R. F.; SILVA, M. A.. Carthamus tinctorius L.: Uma alternativa de cultivo para o Brasil. Acta Iguazu, Cascavel, v.4, n.1, p.26-35. 2015.

SCHAFFNER, R. A.; JÚNIOR, E. S.; DAL POZZO, D. M.; SANTOS, R. F.; NEVES, A. C.; MADALENA, L. C. S.. Extrato de capim napier (Pennisetum purpureum) aplicado no desenvolvimento inicial do Cártamo (Carthamus tinctorius). Acta Iguazu, v.6, n.5, p.223-230, 2017.

SCHRÖDER, D.; KÖPKE, U.. Faba bean (Vicia faba L.) intercropped with oil crops: a strategy to enhance rooting density and to optimize nitrogen use and grain production? Field Crops Research, v.135, p.74-81, 2012. DOI: http://doi.org/10.1016/j.fcr.2012.07.007

A CBPC - Companhia Brasileira de Produção Científica (CNPJ: 11.221.422/0001-03) detém os direitos materiais desta publicação. Os direitos referem-se à publicação do trabalho em qualquer parte do mundo, incluindo os direitos às renovações, expansões e disseminações da contribuição, bem como outros direitos subsidiários. Todos os trabalhos publicados eletronicamente poderão posteriormente ser publicados em coletâneas impressas sob coordenação da Sustenere Publishing, da Companhia Brasileira de Produção Científica e seus parceiros autorizados. Os (as) autores (as) preservam os direitos autorais, mas não têm permissão para a publicação da contribuição em outro meio, impresso ou digital, em português ou em tradução. 